\title{
Identification of DPP4/CTNNB1/MET as a Theranostic Signature of Thyroid Cancer and Evaluation of the Therapeutic Potential of Sitagliptin
}

\author{
Sheng-Yao Cheng ${ }^{1,+}$, Alexander T. H. Wu ${ }^{2,3,4,5,+}{ }^{\mathbb{D}}$, Gaber El-Saber Batiha ${ }^{6} \mathbb{D}$, Ching-Liang Ho ${ }^{7}$, Jih-Chin Lee ${ }^{1}$, \\ Halimat Yusuf Lukman ${ }^{8}{ }^{(D}$, Mohammed Alorabi ${ }^{9}$ (D), Abdullah N. AlRasheedi ${ }^{10}$ and Jia-Hong Chen ${ }^{7, *}$
}

check for updates

Citation: Cheng, S.-Y.; Wu, A.T.H.; Batiha, G.E.-S.; Ho, C.-L.; Lee, J.-C.; Lukman, H.Y.; Alorabi, M.;

AlRasheedi, A.N.; Chen, J.-H. Identification of DPP4/CTNNB1/ MET as a Theranostic Signature of Thyroid Cancer and Evaluation of the Therapeutic Potential of Sitagliptin Biology 2022, 11, 324. https:// doi.org/10.3390/biology11020324

Academic Editors: Shibiao Wan, Yiping Fan, Chunjie Jiang and Shengli Li

Received: 11 December 2021 Accepted: 14 February 2022 Published: 17 February 2022

Publisher's Note: MDPI stays neutral with regard to jurisdictional claims in published maps and institutional affiliations.

Copyright: (C) 2022 by the authors. Licensee MDPI, Basel, Switzerland. This article is an open access article distributed under the terms and conditions of the Creative Commons Attribution (CC BY) license (https:// creativecommons.org/licenses/by/ $4.0 /)$.
1 Department of Otolaryngology-Head and Neck Surgery, Tri-Service General Hospital, National Defense Medical Center, 325, Section 2, Chenggong Road, Taipei 114, Taiwan; gjcheng5032@gmail.com (S.-Y.C.); doc30450@gmail.com (J.-C.L.)

2 TMU Research Center of Cancer Translational Medicine, Taipei Medical University, Taipei 110, Taiwan; chaw1211@tmu.edu.tw

3 The PhD Program of Translational Medicine, College of Science and Technology, Taipei Medical University, Taipei 110, Taiwan

4 Clinical Research Center, Taipei Medical University Hospital, Taipei Medical University, Taipei 110, Taiwan

5 Graduate Institute of Medical Sciences, National Defense Medical Center, Taipei 110, Taiwan

6 Department of Pharmacology and Therapeutics, Faculty of Veterinary Medicine, Damanhour University, Damanhour 22511, Egypt; gaberbatiha@gmail.com

7 Division of Hematology/Oncology, Department of Medicine, Tri-Service General Hospital, National Defense Medical Center, Taipei 11490, Taiwan; charileho22623@gmail.com

8 Department of Chemical Sciences, Biochemistry Unit, College of Natural and Applied Sciences, Summit University Offa, Offa PMB 4412, Nigeria; halimatyusuf40@summituniversity.edu.ng

9 Department of Biotechnology, College of Sciences, Taif University, Taif P.O. Box 11099, Saudi Arabia; maorabi@tu.edu.sa

10 Otolaryngology-Head \& Neck Surgery Department, College of Medicine, Jouf University, Sakaka P.O. Box 2014, Saudi Arabia; analrashedi@ju.edu.sa

* Correspondence: ndmc_tw.tw@yahoo.com.tw

$+\quad$ These authors contributed equally to this work.

Simple Summary: In recent years, the incidence of thyroid cancer has been increasing globally, with papillary thyroid cancer (PTCa) being the most prevalent pathological type. Although PTCa has been regarded to be slow growing and has a good prognosis, in some cases, PTCa can be aggressive and progress despite surgery and radioactive iodine treatment. Therefore, searching for new targets and therapies is required. We utilized bioinformatics analyses to identify critical theranostic markers for PTCa. We found that DPP4/CTNNB1/MET is an oncogenic signature that is overexpressed in PTCa and associated with disease progression, distant metastasis, treatment resistance, immunoevasive phenotypes, and poor clinical outcomes. Interestingly, our in silico molecular docking results revealed that sitagliptin, an antidiabetic drug, has strong affinities and potential for targeting DPP4/CTNNB1/MET signatures, even higher than standard inhibitors of these genes. Collectively, our findings suggest that sitagliptin could be repurposed for treating PTCa.

Abstract: In recent years, the incidence of thyroid cancer has been increasing globally, with papillary thyroid cancer (PTCa) being the most prevalent pathological type, accounting for approximately $80 \%$ of all cases. Although PTCa has been regarded to be slow growing and has a good prognosis, in some cases, PTCa can be aggressive and progress despite surgery and radioactive iodine treatment. In addition, most cancer treatment drugs have been shown to be cytotoxic and nonspecific to cancer cells, as they also affect normal cells and consequently cause harm to the body. Therefore, searching for new targets and therapies is required. Herein, we explored a bioinformatics analysis to identify important theranostic markers for THCA. Interestingly, we identified that the DPP4/CTNNB1/MET gene signature was overexpressed in PTCa, which, according to our analysis, is associated with immuno-invasive phenotypes, cancer progression, metastasis, resistance, and unfavorable clinical outcomes of thyroid cancer cohorts. Since most cancer drugs were shown to exhibit cytotoxicity 
and to be nonspecific, herein, we evaluated the anticancer effects of the antidiabetic drug sitagliptin, which was recently shown to possess anticancer activities, and is well tolerated and effective. Interestingly, our in silico molecular docking results exhibited putative binding affinities of sitagliptin with DPP4/CTNNB1/MET signatures, even higher than standard inhibitors of these genes. This suggests that sitagliptin is a potential THCA therapeutic, worthy of further investigation both in vitro and in vivo and in clinical settings.

Keywords: sitagliptin; thyroid cancer (THCA); papillary thyroid cancer (PTCa); thyroidectomy; metastasis; drug resistance

\section{Introduction}

Thyroid cancer (THCA) is the most prevalent malignancy of the endocrine system, and the 9th most common cancer in the world [1,2], accounting for approximately 600,000 newly diagnosed cases annually on a global scale [3], with high rates of morbidity reported in recent years [4]. THCA is divided into various subtypes, including anaplastic thyroid cancer (ATC), papillary thyroid carcinoma (PTCa), and follicular thyroid carcinoma (FTC), with PTCa being the most prevalent, as it accounts for approximately $85 \%$ of THCA [5,6]. PTC and FTC are well-differentiated thyroid cancers with an optimal prognosis of about 10 years disease-specific survival [7]. However, the ATC is poorly differentiated with proliferative stem-cell-like properties, resistance to therapies, and accounts for the majority of thyroid-cancer-related deaths $[8,9]$. The rapid increase in thyroid cancer, particularly PTCa, has been accredited to the availability and sensitive use of ultrasonography and other diagnostic imaging modalities $[10,11]$, which have likely led to a massive detection and diagnosis of a large reservoir of subclinical, indolent lesions of the thyroid [12,13]. Studies have also implicated obesity, hormonal imbalance, metabolic syndromes, and environmental pollutants in the development of PTCa [14].

Patients with PTCa usually show good clinical outcomes compared with other cancers; however, there is also a very high rate of relapse post-treatment, leading to distant metastasis $[15,16]$. About $11 \%$ of patients with PTC present with distant metastases outside the neck and mediastinum [17]. Moreover, long-term survival outcomes for aggressive PTC subgroups exhibit heterogeneous clinical behavior and a wide range of mortality risks, suggesting that treatment should be tailored to specific histologic subtypes [18]. The diagnostic criteria for PTC allow it to demonstrate various histological features and growth patterns; different variants of PTCa are recognized, including classic, microcarcinoma, encapsulated, follicular, diffuse sclerosing, tall cell, columnar cell, cribriform-morular, hobnail, solid, oncocytic, spindle cell, clear cell, and Warthin-like variants [19]. However, among these variants, tall cell, columnar cells, and hobnail variants are of undoubted clinical significance, since they are aggressive variants associated with aggressive clinicopathological features and worse prognosis than for classic and encapsulated PTC [20-22].

Surgery, endocrine therapy, and radioiodine therapy are well-known therapy regimens for PTCa, offering a good prognosis; however, the aggressive variants of PTCa progress despite surgery and radioactive iodine treatment [23]. In addition, tumor recurrence in PTCa is associated with therapeutic resistance which increases the death toll in patients [24-26]. Unfortunately, an upsurge in the incidence of aggressive PTCs was observed at a rate higher than that seen in well-differentiated PTCs or anaplastic thyroid carcinomas (ATCs) in the past two decades in a study of a large cohort of thyroid cancers [22]; therefore, there is an urgent need to identify novel diagnostic and prognostic molecular biomarkers that could also be used as molecular targets for the development of new drugs or in repurposing existing drugs for the treatment of PTCa.

Increasing evidence shows that dipeptidyl aminopeptidase IV (DPP IV) is associated with cancer development and progression [27,28]; DPP4 is an adenosine deaminase complex protein, and was demonstrated to be upregulated in THCA, particularly in PTCa, 
and is associated with tumor aggression and poor prognoses [29-31]. Moreover, high expression of DPP4 was shown to promote distance metastasis and stemness in esophageal adenocarcinoma and colorectal cancer [32,33]. However, the prognostic role of DPP4 expression and its role in THCA metastasis remains elusive $[7,29,31]$. Studies have shown that DPP4 and b-catenin crosstalk to regulate critical cellular processes, including motility and invasion [34]. A study involving lung cancer patients has revealed that the expression levels of $\beta$-catenin correlate with DPP4 expression [35] and contributed to tumor metastasis $[34,36]$. An experimental study has also reported that activating mutation of Ctnnb1 induced DPP4 overexpression in epidermal keratinocytes of LRIG1+ ${ }^{+}$stem cells [37]. Research has illuminated that inhibitors of DPP4 exert their therapeutic effect via modulation of the Wnt/ $\beta$-catenin signaling pathway [38]. Sitagliptin, an inhibitor of DPP4, has also been reported to provide renal protection via inhibition of the tubulointerstitial Wnt/ $\beta$-catenin signaling pathway in diabetic nephropathy [39].

Accumulating studies demonstrated a pivotal correlation between distant metastasis in PTCa and MET (MET proto-oncogenic receptor tyrosine kinase) [40]. Approximately $70 \%$ of PTCas were reported to overexpress the MET gene, and it is associated with poor prognoses [41]. In addition, Rossana et al. also demonstrated that higher expression levels of MET in PTCa promoted cancer growth and distance metastasis [42,43]. MET is a transmembrane tyrosine kinase identified as a high-affinity receptor for hepatocyte growth factor (HGF), and both MET and HGF were demonstrated to be expressed in PTCa [42], and consequently promote progression and secondary metastasis [44]. Additionally, MET was shown to activate $\beta$-catenin (CTNNB1), an important component of the canonical Wnt pathway $[45,46]$. CTNNB1 was recently reported to be mutated in PTCa, and to ultimately promote cancer development and stemness $[47,48]$. Moreover, upregulated MET was also demonstrated to regulate the expression of mitogen-activated protein kinase $(M A P K)$, phosphatidylinositol 3-kinase $(P I 3 K) / A K T$, signal transducer and activator of transcription 3 (STAT3), and nuclear factor (NF) $\kappa B$ pathways in THCA $[40,49]$. This suggests that MET is a crucial target gene in THCA, and worthy of further investigation. To date, most drugs used for cancer treatment are cytotoxic and usually not specific to cancer cells, but also affect normal cells; therefore, there is still a huge gap in finding more sensitive and specific drugs for cancer. Recent studies suggested an association between cancer occurrence and antidiabetic medicaments. Sitagliptin is a standard inhibitor of DPP4, widely used for treating diabetes, and was shown to possess anticancer activities, as well as being efficacious and well tolerated [50]. In the present study, we predicted the potential anticancer activities of sitagliptin as a target for DPP4/CTNNB1/MET oncogenic signatures, which are overexpressed in THCA.

\section{Materials and Methods}

\subsection{Microarray Data Acquisition and Identification of Differentially Expressed Genes (DEGs)}

Gene expressions of four THCA datasets (GEO3467, GEO36787, GEO6004, and GEO33630) were extracted from the NCBI gene expression omnibus. The acquired datasets were further analyzed using GEO2R (https: / / www.ncbi.nlm.nih.gov/geo/geo2r / accessed on 5 September 2021), and results contained DEG profiles from THCA patients compared to normal samples. To control the false discovery rate (FDR), the Benjamini-Hochberg adjustment was applied to $p$ values (adjusted (adj.) $p$ values), to moderate the balance between detection of significant genes and possible false-positive values. The fold-change (FC) threshold was set to 1.5, and adj. $p<0.05$ was considered statistically significant. Venn diagrams were constructed using the Bioinformatics and Evolutionary Genomics (BEG) online tool (http:/ / bioinformatics.psb. ugent.be/webtools/Venn/ accessed on 6 September 2021).

\subsection{Differential Expression of the THCA Gene Hub}

Differential expressions of THCA gene profiles between tumor tissues and normal adjacent tissues of the Cancer Genome Atlas (TCGA) database were analyzed using UALCAN (http:/ / ualcan.path.uab.edu accessed on 12 September 2021), an online web portal used to 
identify gene expression levels between primary tumors compared to normal tissue samples [51]. Moreover, we explored the cBioPortal online web tool (https: / /www.cbioportal.org accessed on 19 September 2021), which categorizes gene alterations based on percentages of individual genes due to amplification [52]. For further analysis, we used the cBioPortal correlation sub-tool to determine gene expression correlations with positive Spearman and Pearson correlation coefficients with $p<0.05$ as statistically significant.

\subsection{Comparisons of DPP4/CTNNB1/MET Expressions in Normal, Primary, and Metastatic Tumor of Thyroid Cancer Cohorts}

To compare expression levels of the DPP4/CTNNB1/MET oncogenes among normal, tumor, and metastatic tissues, we explored the tumor, normal, and metastatic plot (TNMplot), (https:/ / tnmplot.com/analysis / accessed on 21 September 2021), an RNA-sequence-based rapid analysis, which is used to compare data of selected genes [53]. Data were compared using the Kruskal-Wallis test, which is a method used to test samples originally from the same distribution of specimens, followed by Dunn's test, which assesses the significance of gene expressions in promoting THCA tumor metastasis, with $p<0.05$ considered statistically significant.

\subsection{Interaction Network and Gene Enrichment Analysis}

An interaction network analysis was constructed using the Search Tool for the Retrieval of Interacting Genes/Proteins (STRING, https:/ / string-db.org/ accessed on 25 September 2021) database [54], and GeneMANIA [55] (http://genemania.org/data accessed on 28 September 2021), which are online web tools developed to analyze interaction networks. The STRING database was used under a high confidence of 0.700 , and protein enrichment of $p<6.0 \times 10^{-03}$ was obtained. Interactions among genes were analyzed according to correlations based on experimental data (pink), gene neighborhoods (green), gene fusion (red), gene co-occurrences (blue), and gene co-expression (black). Moreover, we explored the Network Analyst user-friendly online tool (https:/ / www.networkanalyst.ca/ accessed on 5 October 2021) to analyze co-expressed gene enrichment from the biological processes databases; herein we applied the Igraph $\mathrm{R}$ package visualization tool for analysis [56]. Furthermore, gene ontology (GO), biological processes (BPs), and Kyoto Encyclopedia of Genes and Genomes (KEGG) enrichment analyses were analyzed using FunRich software (http: / / www.funrich.org accessed on 9 October 2021), an open access, stand-alone functional enrichment and network analytical tool [57].

\subsection{Analysis of Genomic Alterations and Mutations of the DPP4/CTNNB1/MET Oncogenes in THCA}

Mutations of DPP4/CTNNB1/MET oncogenic expressions in THCA were analyzed using cBioPortal software. Herein, we analyzed altered frequencies of these oncogenes in THCA. Furthermore, we explored the muTarget platform (https: / www.mutarget.com/ accessed on 11 October 2021), a platform linking changes in gene expressions and the mutation status of solid tumors, based on a genotype analysis, to determine associations between DPP4/CTNNB1/MET and alterations in gene expressions in THCA. Differences in expressions between the mutant group and wild-type (WT) group were considered statistically significant at $p<0.05$.

\subsection{Correlations of DPP4/CTNNB1/MET Expressions and Tumor Infiltration Levels of Immune and Immunosuppressive Cells in THCA}

The Tumor Immune Estimation Resource (TIMER) (https: / / cistrome.shinyapps.io/ timer / accessed on 18 October 2021) is an online computational tool used to analyze the nature of tumor immune interactions across different cancer types [58]. Herein, we determined correlations of DPP4/CTNNB1/MET expressions and tumor infiltration levels of tumor associated macrophages (M2 TAM), regulatory T cell (Treg), cancer-associated fibroblast (CAF), and cluster of differentiation 8-positive (CD8 ${ }^{+} \mathrm{T}$ cell), using a set of gene markers of immune infiltration model, as described previously $[59,60]$. The strength 
of correlations between the genes and immune cells is reflected by the purity-adjusted partial Spearman's rho value, where a value of $r \geq 1$ means a perfect positive correlation and a value of $\mathrm{r} \leq-1$ means a perfect negative correlation, with $p<0.05$ considered statistically significant.

\subsection{In Silico Molecular Docking of the DPP4/CTNNB1/MET Oncogenes with Sitagliptin}

The potential inhibitory effects of sitagliptin on THCA hub genes of DPP4, CTNNB1, and MET were analyzed by molecular docking simulations, compared to the standard inhibitors of CTNNB1 and MET of PNU-74654 and crizotinib, respectively. The 3D structures of sitagliptin (CID: 4369359), PNU-74654 (CID:9836739), and crizotinib (CID:116250) were retrieved from the pubchem database (https:/ / pubchem.ncbi.nlm.nih.gov/ accessed on 22 October 2021), in the spatial data file (SDF) format, and consequently converted to PDB file format using the PyMOL visualization tool [61] (https://pymol.org/2/ accessed on 22 October 2021), while the crystal structures of DPP4 (PDB:2ONC), CTNNB1 (PDB:1JDH), and MET (PDB:3DKF) were downloaded from the protein database (PDB), (https: / / www.rcsb.org/ accessed on 22 October 2021), in PDF file format. File preparation for molecular docking was as described in previous studies [62-64]. Using autodock software, an in silico molecular docking tool [65], all PDB files were converted to PDBQT file formats, and docking was accordingly performed using autodock, as described previously [66,67]. For further analysis, we used PyMol to analyze ligand-receptor interactions in 3D view, and finally used the discovery studio web tool [68] for data interpretation.

\section{Results}

\subsection{Identification of Common Oncogenes in THCA}

Microarray datasets were downloaded from the NCBI-GEO database to identify DEGs in THCA. Commonly expressed oncogenes were identified from THCA tissues compared to adjacent normal tissues obtained from different studies. Volcano plots were used to show all DEGs from all selected datasets, and accordingly, the GSE3467, GSE3678, GSE6004, and GSE33630 datasets, respectively, displayed 691, 449, 1455, and 789 upregulated genes and 1088, 1232, 2890, and 1568 downregulated genes (Figure 1A-D). The relatedness of all samples in each dataset to each other was analyzed by uniform manifold approximation and projection (UMAP), in which the number of nearest neighbors was used for calculations as indicated in each plot (Figure 1E-H). In total, 123 overlapping genes were obtained using Venn diagrams, as observed from THCA tissues compared with normal tissues (Figure 1I,J). We further used these genes for further analysis of THCA in this study.

\subsection{DPP4/CTNNB1/MET Expressions Are Associated with THCA Progression, Metastasis, and} Worse Prognosis of THCA Cohorts

Our differential expression analysis revealed that the $(\mathrm{m}) \mathrm{RNA}$ expression levels of DPP4/CTNNB1/MET were higher in THCA tumor tissues compared with adjacent normal tissues (Figure 2A). We further analyzed the role of DPP4, CTNNB1, and MET expressions in promoting THCA progression and tumor metastasis. Interestingly, our analysis revealed that the mRNA expressions levels of DPP4/CTNNB1/MET were more elevated in stage IV of THCA cancer (Figure 2B), and were significantly elevated in metastasis tumor compared with the primary tumor (Figure 2C). In addition, we found expression correlation among the DPP4/CTNNB1/MET signature in THCA cohorts (Figure 2D). Furthermore, we constructed a Kaplan-Meier (KM) plot of patients' survival and found that higher expression levels of the DPP4/CTNNB1/MET genes were associated with shorter survival duration of the cohorts (Figure 2E). Although the KM plot revealed no significant $(p>0.05)$ difference in the overall survival between cohorts with high and cohorts with low expression levels of DPP4, our analysis revealed that the disease-free survival of the cohorts was significantly $(p<0.048)$ higher in the low-DPP4-expression group when compared with the high-expression group. Collectively, our findings strongly suggested that the expression levels of DPP4/CTNNB1/MET signature are associated with THCA progression, metas- 
tasis, and worse prognosis of THCA cohorts, hence serving as important biomarker for diagnosis, prognosis, and therapeutic exploration in THCA.
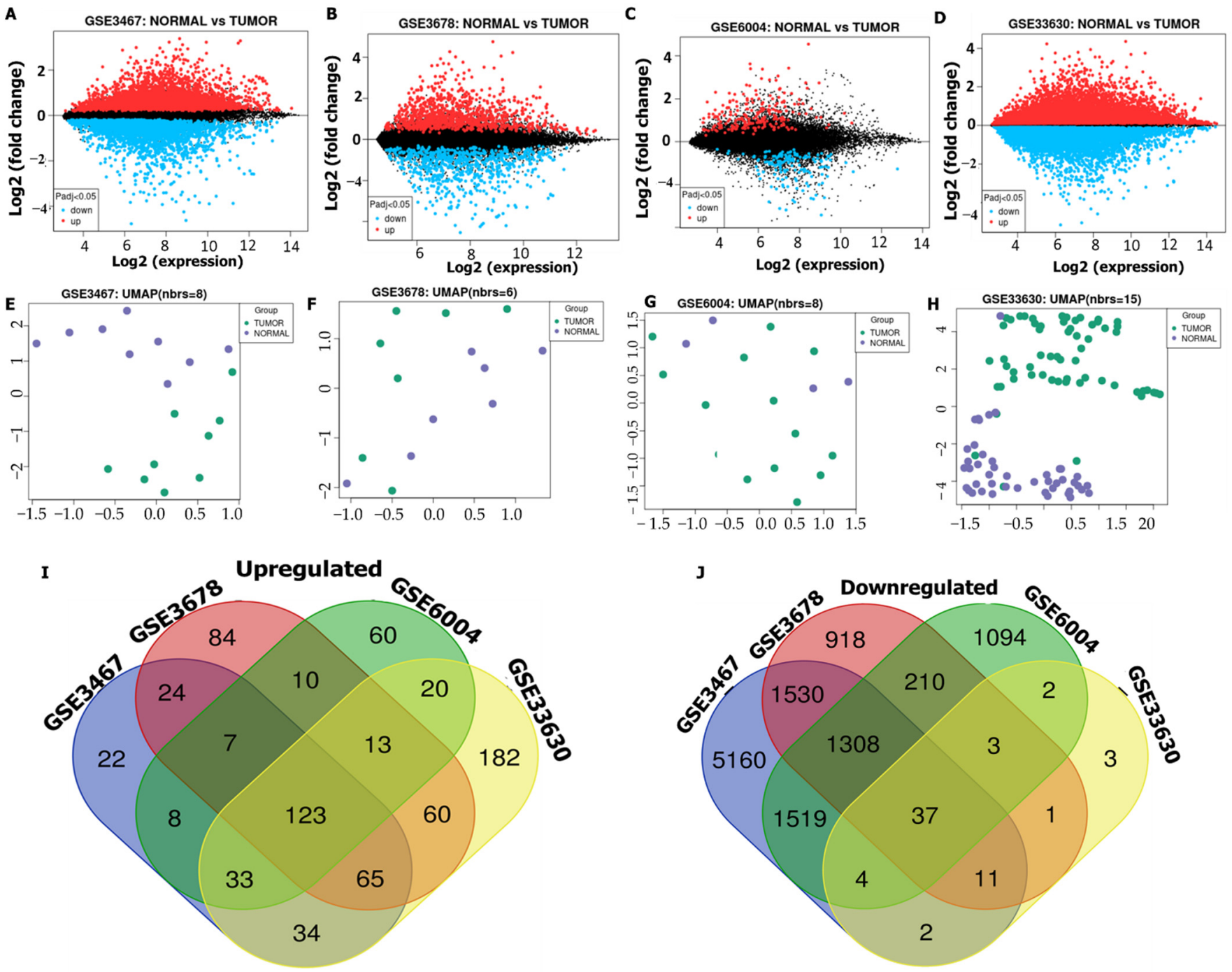

Figure 1. Differentially expressed genes (DEGs) in thyroid cancer (THCA). (A-D) Volcano plots showing DEGs extracted from the GSE3467, GSE3678, GSE6004, and GSE33630 microarray datasets, between cancer tissues compared with normal adjacent tissues, with upregulated genes (red), downregulated genes (blue), and non-significant genes (black). (E-H) Two-dimensional (2D) visualization of UMAP dimensionality reduction in THCA tumor tissues (green) compared with normal tissues (purple). (I,J) Venn diagram of 123 overlapping DEGs between normal colon tissues and tumor tissues.

\subsection{DPP4/CTNNB1/MET Genes Are Frequently Altered and Their Mutations Are Linked to Genetic Expressions in THCA}

Mutations of DPP4/CTNNB1/MET oncogenes in THCA were analyzed using the cBioPortal tool, and altered frequencies were based on percentages of individual genes due to amplification. Analytical results showed respective amplification of DPP4, CTNNB1, and MET occur in 3\%, 6\%, and 6\% of THCA cohorts respectively. These included deep deletions (blue), mRNAs (red), proteins (red), mutations (green), and structural variants (purple) (Figure 3A-D). For further analysis, we compared associations between alterations in DPP4 and MET oncogenic expressions with mutations of the top genes expressed in THCA at the target level, and according to our findings, BRAF mutations promoted increased expression levels of DPP4 and MET compared with the WT. Patients with high expression levels of 
DPP4 and MET signatures exhibited worse clinical outcomes compared with patients with low expression levels (Figure 3E,F).

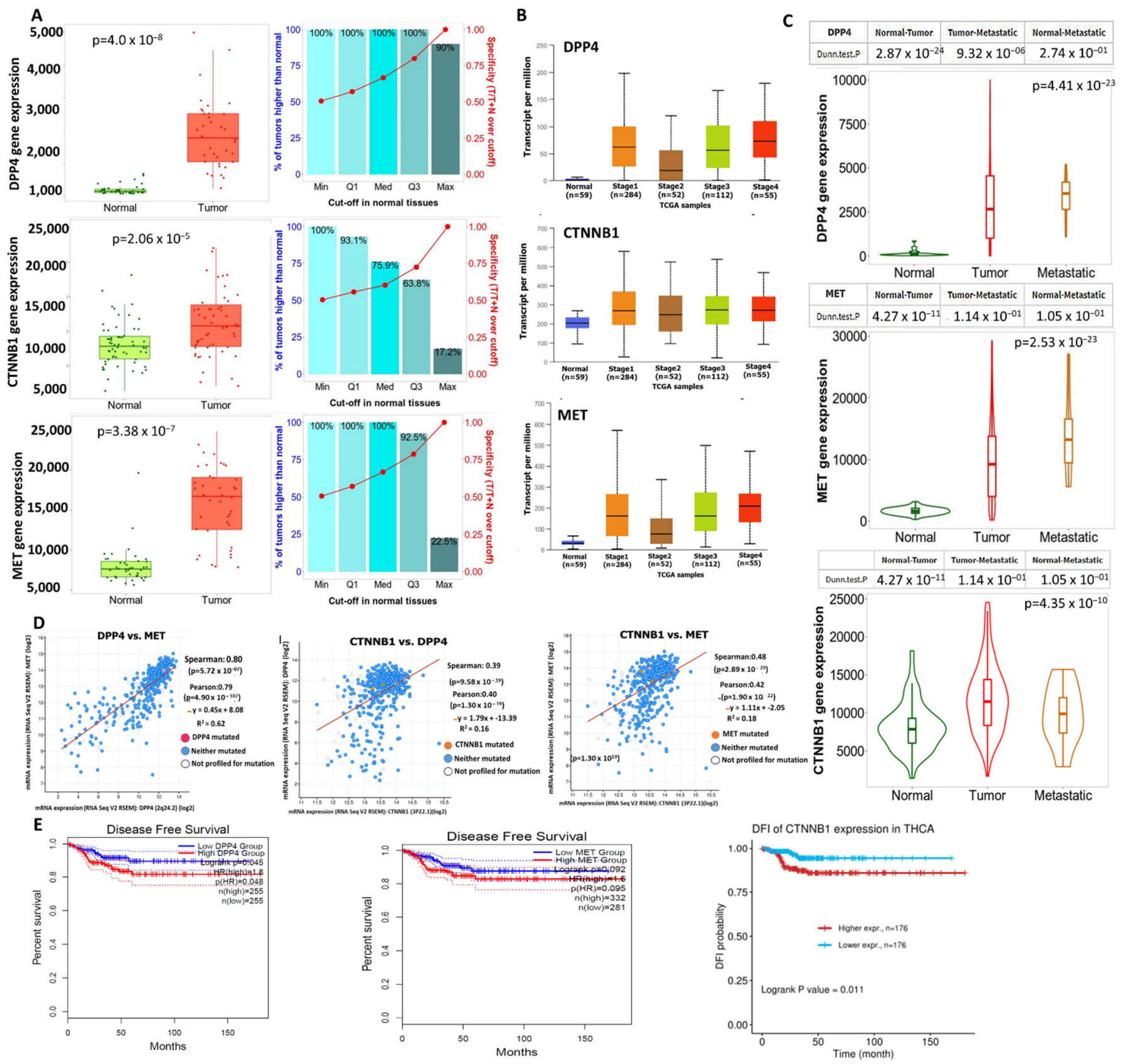

Figure 2. Overexpression of DPP4/CTNNB1/MET mRNAs, associated with thyroid cancer (THCA) progression. Differential expression levels of DPP4/CTNNB1/MET between (A) THCA tumor and adjacent normal tissue, $(\mathbf{B})$ tumor stages, and $(\mathbf{C})$ between primary and metastatic tumor of TCGA cohort. (D) Correlations of DPP4 with MET, CTNNB1 with DPP4, and MET with CTNNB1 oncogenic expressions in THCA. (E) KPM plots of survival ratio between THCA cohorts with high and those with low expression levels of DPP4/CTNNB1/MET. 
A

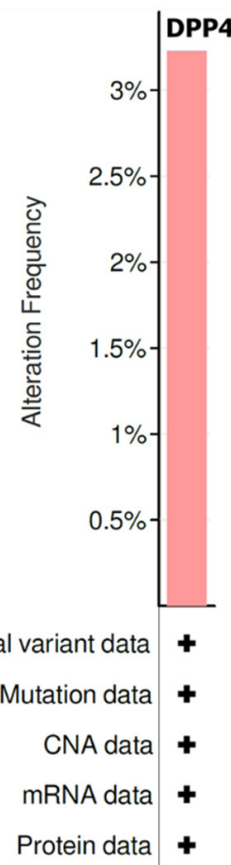

B
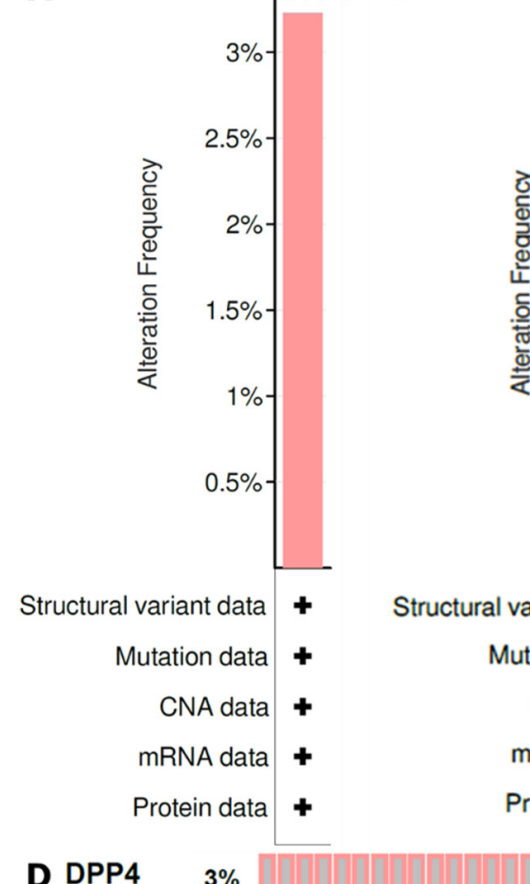

D DPP4

$3 \%$

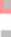

CTNNB1 $6 \%$

MET $\quad 6 \%$

Deep Deletion
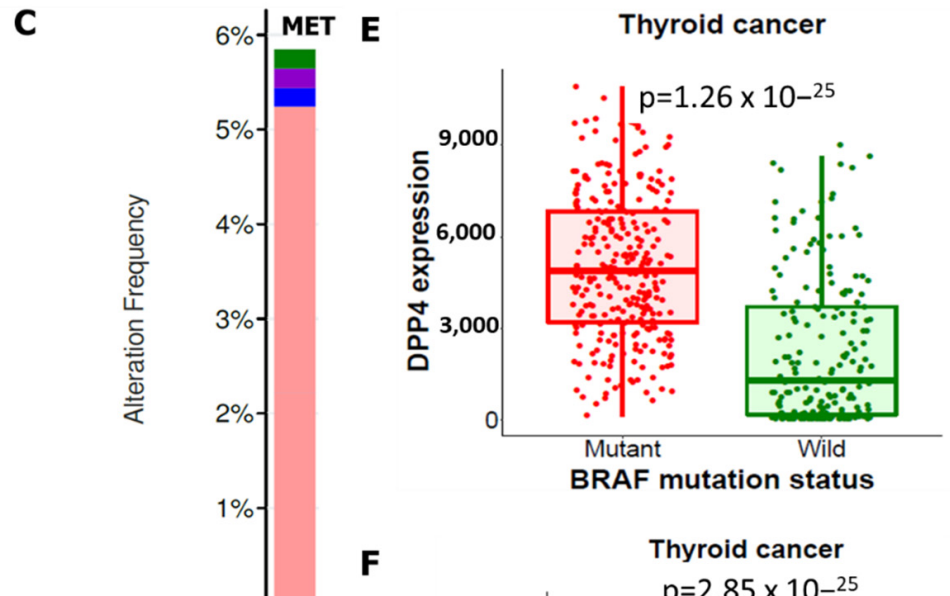

$\mathbf{F}$

\section{Thyroid cancer} $p=2.85 \times 10^{-25}$

Structural variant data Mutation data CNA data mRNA data Protein data +

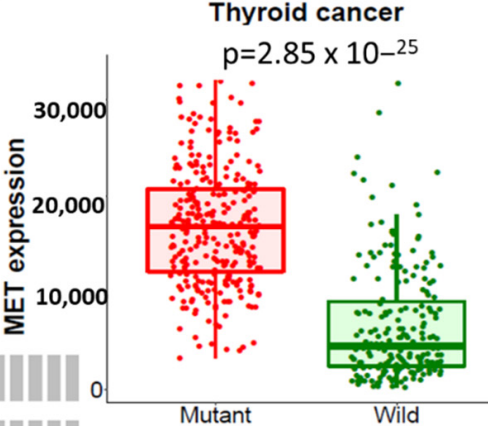

BRAF mutation status

Figure 3. Genetic mutations based on percentages due to amplification of (A) DPP4 (3\%), (B) CTNNB1 (6\%), and (C) MET (6\%), including deep deletions (blue), mRNAs (red), proteins (red), mutations (green), and structural variants (purple). (D) Individual genetic alteration profile of DPP4/CTNNB1/MET in THCA. (E,F) BRAF mutations promoted overexpression of DPP4 and MET compared with the wild type, with $p<0.05$ considered statistically significant.

\subsection{DPP4/CTNNB1/MET Genes Potentially Promote Tumor Growth by Interacting with Different Oncogenic Targets/Pathways}

We applied the STRING database and GeneMANIA online web tools developed to analyze interaction networks among four selected oncogenes. Herein, we considered experimental data (pink), gene neighborhoods (green), gene fusion (red), gene co-occurrences (blue), and gene co-expressions (black) when analyzing interactions. As expected, interaction networks were identified between DPP4 and CTNNB1, MET and DPP4, CTNNB1 and MET, HFG and MET, DPP4 and CTNND1, and GSK3B and CTNND1 within the network clustering. An average local clustering coefficient of 0.787 was obtained, with an expected number of edges of 21 and interaction $p$ value of 0.006 (Figure 4A,B). For further analysis, we conducted a gene enrichment analysis and predicted GO processes using network analytical software, which showed co-expressions of CTNNB1, GSK3B, AXIN1, and MET to be enriched in the BP databases. Herein, we applied the Igraph R package visualization tool for analysis (Figure 4C). For more analysis, we used FunRich software to validate GO including BPs and KEGG enrichment analyses. The top five enriched BPs included chromosomal segregation, signaling transduction, cell communication, regulation of the cell cycle, and protein metabolism, while pathways involved in interactions included E-cadherin signaling in the nascent cadherin junction, stabilization and expression of adherens junctions, E-cadherin signaling events, posttranscriptional regulation of adherens junction stability, and N-cadherin signaling events (Figure 4D,E), with $p<0.05$ considered significant. 

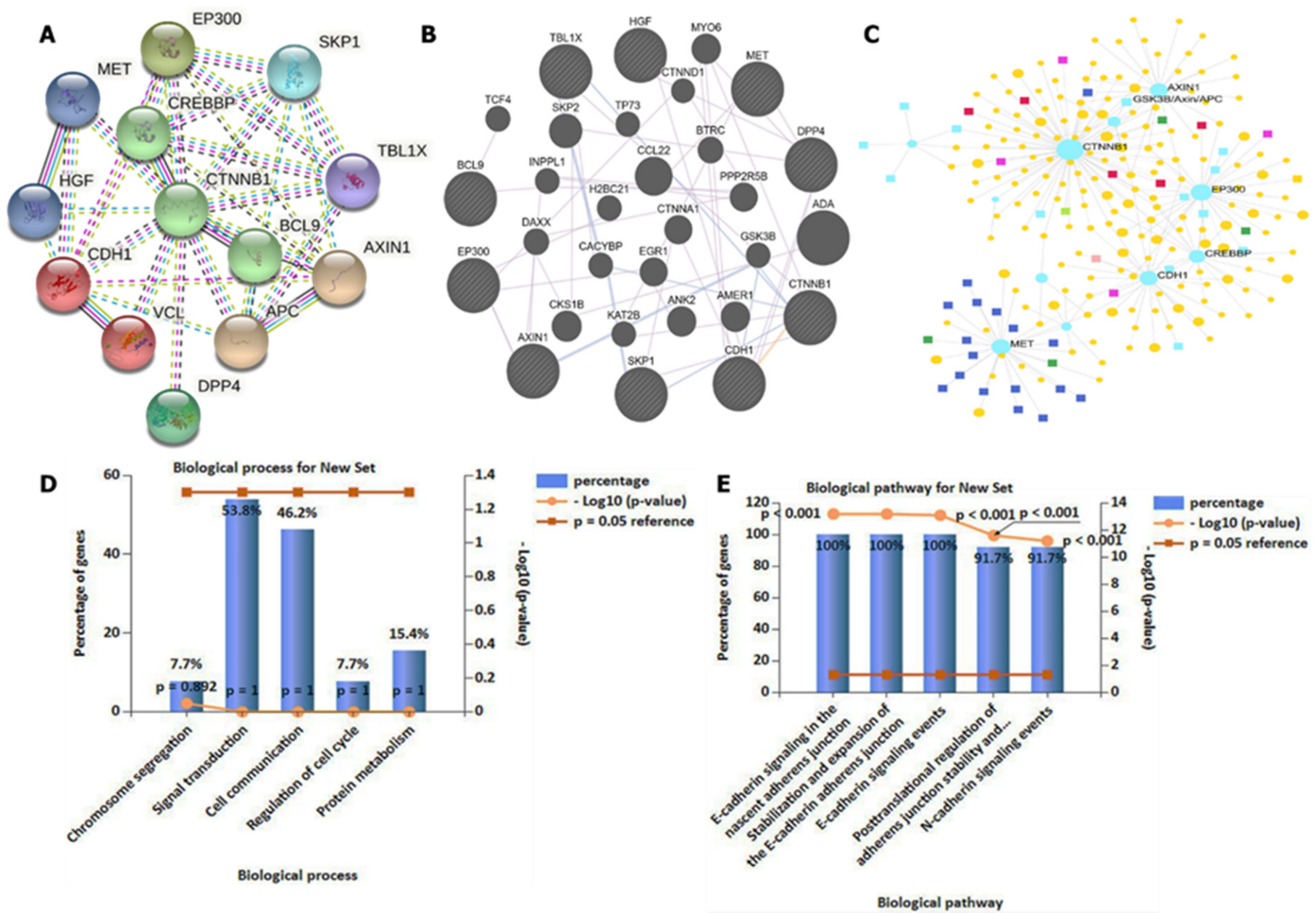

Figure 4. DPP4/CTNNB1/MET gene interactions co-expressed in the same clustering network. $(\mathbf{A}, \mathbf{B})$ Interaction networks showing co-expression between DPP4 and CTNNB1, MET and DPP4, CTNNB1 and MET, HFG and MET, DPP4 and CTNND1, and GSK3B and CTNND1 within the network clustering. An average local clustering coefficient of 0.787 was obtained, with an expected number of edges of 21 and an interaction $p$ value of 0.006. (C) Gene enrichment analysis gene ontology (GO) showed enrichment in co-expressions of CTNNB1, GSK3B, AXIN1, and MET in biological processes. (D,E) Validation of GO, involving enrichment of the top five pathways involved, with $p<0.05$ considered significant.

\subsection{High Expression Levels of DPP4/CTNNB1/MET Are Associated with Immunosuppressive Phenotypes of THCA Tissues}

We queried the association between the mRNA expression levels of DPP4/CTNNB1/MET and tumor infiltrations of immunosuppressive cells using the TCGA cohorts. Interestingly, we found that the mRNA expression levels of DPP4/CTNNB1/MET are inversely associated with tumor purity (Figure 5A). In addition, the high expression levels of the DPP4/CTNNB1/MET correlate positively (all $p<0.001$, cor $>0.3$ ) with the infiltration levels of tumor-associated macrophages (M2 TAM Figure 5B), regulatory T cell (Treg, Figure 5C), and cancer-associated fibroblast (CAF, Figure 5D) in thyroid cancer cohorts (Figure 5). In contrast, a strong negative association (all $p<0.001$, cor $<0$ ) was observed between the mRNA expression levels of DPP4/CTNNB1/MET and the immune infiltration level of CD8 ${ }^{+} \mathrm{T}$ cell (Figure 5E), an antitumor T cell subtype. Collectively, these findings strongly suggested that high expression levels of DPP4/CTNNB1/MET are associated with immunosuppressive phenotypes via a mechanism involving $\mathrm{T}$ cell exclusion in THCA tissues. 


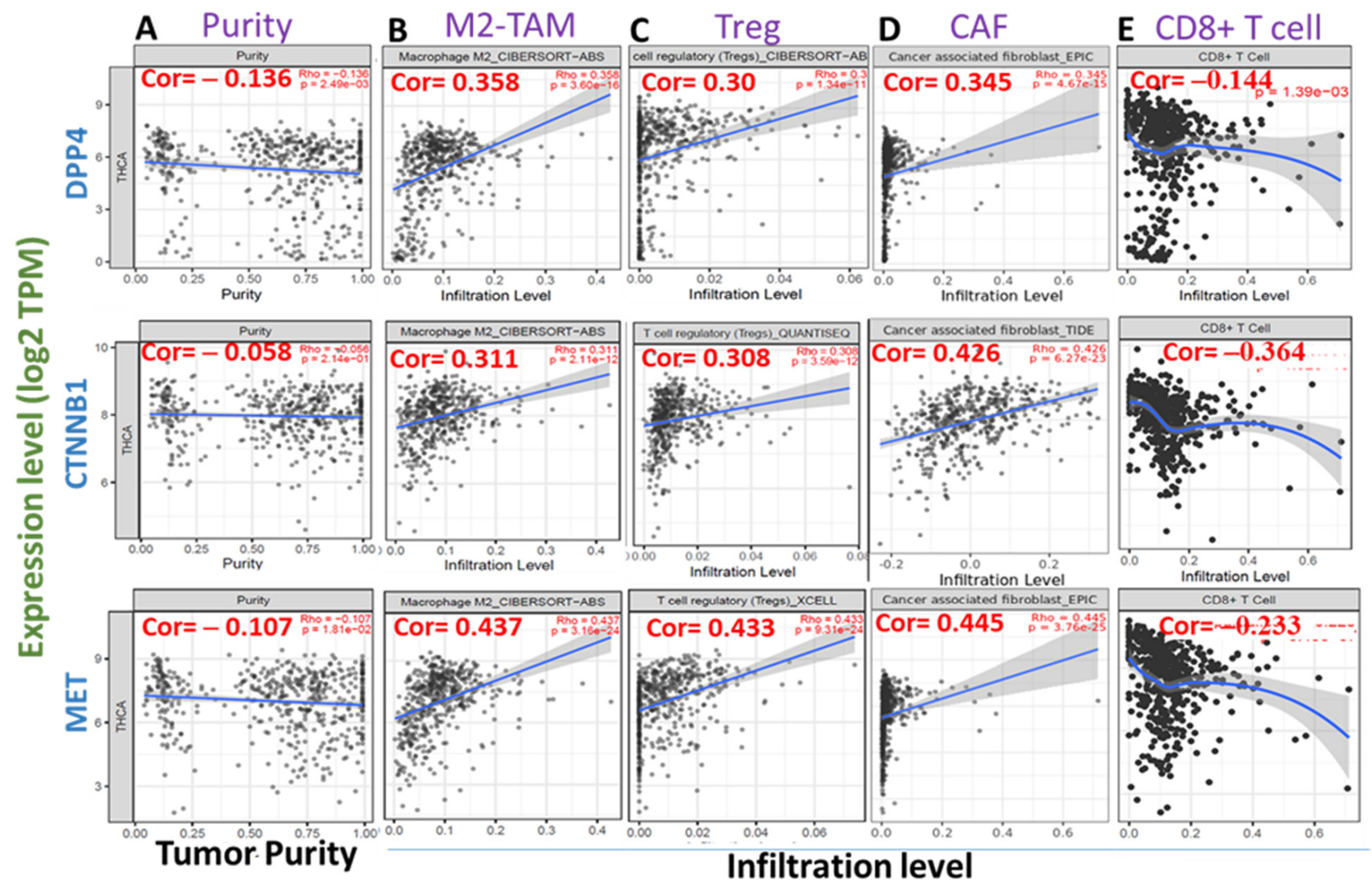

Figure 5. High expression levels of DPP4/CTNNB1/MET are associated with immunosuppressive phenotypes of THCA tissues. Scatterplots of DPP4/CTNNB1/MET expression correlations with $\mathrm{t}(\mathbf{A})$ tumor purity, and infiltration levels of (B) tumor-associated macrophages (M2 TAM), (C) regulatory $\mathrm{T}$ cell (Treg), (D) cancer-associated fibroblast (CAF), and (E) CD8 ${ }^{+} \mathrm{T}$ cell. The strength of correlations between the genes and immune cells is reflected by the purity-adjusted partial Spearman's rho value, where a value of $\mathrm{r} \geq 1$ means a perfect positive correlation and a value of $\mathrm{r} \leq-1$ means a perfect negative correlation, with $p<0.05$ considered statistically significant.

\subsection{Molecular Docking Reveals Higher Inhibitory Effects of Sitagliptin on the DPP4 Oncogene}

Our in silico molecular docking analysis revealed that sitagliptin exhibited higher binding energy of $-8.6 \mathrm{kcal} / \mathrm{mol}$ with the DPP4 oncogene. Further analysis of the docking results showed that sitagliptin bound to the binding pocket of the DPP4 gene by hydrogen bonds with shorter binding distances at TRY631 (2.07 $)$ and ARG125 (2.71 ̊̊), and was further stabilized by a salt bridge, van der Waals forces, carbon-hydrogen bonds, Pi-Pi stacked, Pi-Pi T-shaped, amide Pi-stacked, and Pi-alkyl around the sitagliptin backbone (Figure 6).

3.7. Molecular Docking Revealed Potential Inhibitory Effects of Sitagliptin on the CTNNB1 Oncogene

Our docking analysis revealed that sitagliptin exhibited high binding energy of $-7.3 \mathrm{kcal} / \mathrm{mol}$ with the CTNNB1 oncogene, compared with its Food and Drug Administration (FDA)-approved inhibitor, PNU-74654, which showed a lower binding affinity of $-6.7 \mathrm{kcal} / \mathrm{mol}$. Further analysis of the docking results showed that sitagliptin bound to the binding pocket of the CTNNB1 oncogene by 4 conventional hydrogen bonds and shorter binding distances with CYS466 (2.03 $⿱$ ) , LYS508 (2.51 $)$, SER20 (1.87 $)$, and ARG469 $(1.03 \AA)$. The interactions were further stabilized by van der Waals forces with ALA463, PRO463, PHE21, ASP459, and LEU18, halogen (fluorine) with GLU17, PRO505, GLU462, 
and GLU24, and Pi-alkyl with VAL564 and ILE17 around the sitagliptin backbone. The results were further compared with the PNU-74654/CTNNB1 complex, which is bound to the binding pocket of the CTNNB1 oncogene by only two conventional hydrogen bonds and longer binding distances compared with the sitagliptin/CTNNB1 complex. The interactions were further stabilized by van der Waals forces with SER32, TYR306, and SER335, amide Pi-stacked with GLU375, and Pi-cation with GLU28, LYS345, and ARG342 around the PNU-74654 backbone. This suggests that sitagliptin has a high potential to target $\beta$-catenin (CTNNB1), compared with its standard inhibitor, PNU-74654 (Figure 7).

A

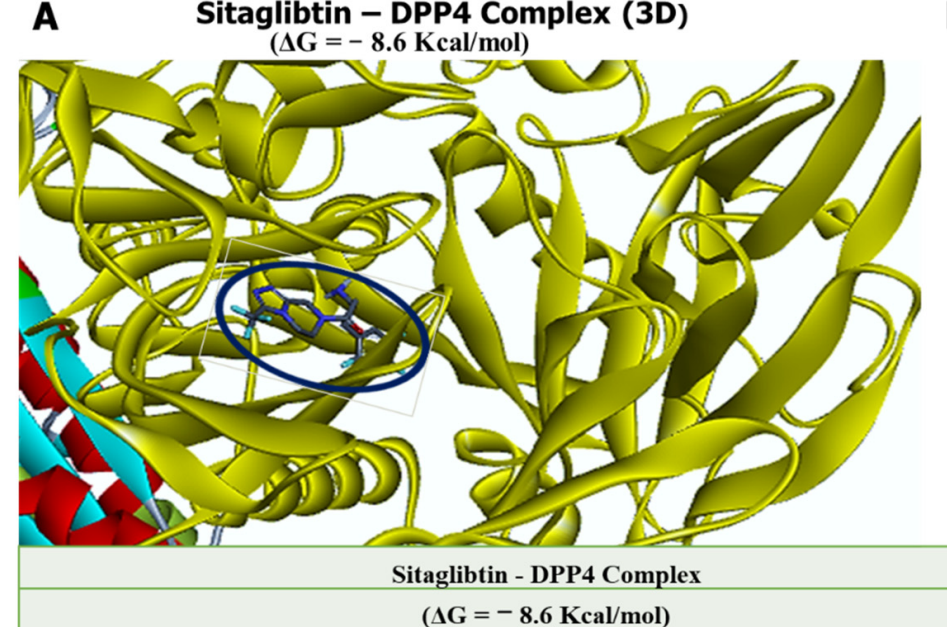

Type of interactions and number of bonds

Conventional Hydrogen bond (2)

Salt Bridge

Van der Waals forces

Carbon hydrogen bond

Pi-Pi Stacked

Pi-Pi T shaped

Amide Pi-Stacked

Pi-Alkyl

Glu205, GLU206
TRP629, VAL656, VAL711, HIS740, ASN710

SER630

TYR547

TYR666

TYR662

PHE357
B

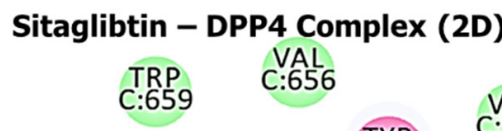

V:711

C: 740
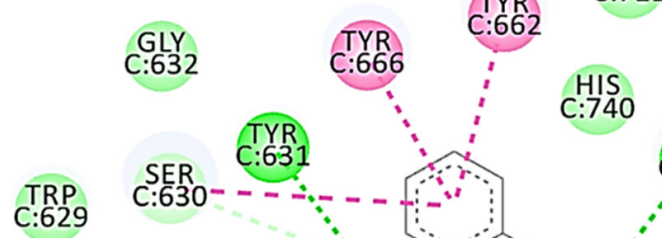

ASN

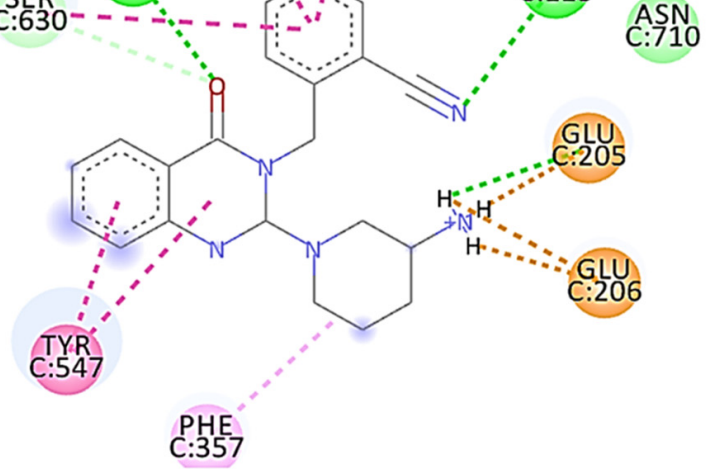

Interactions

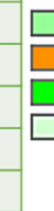

Figure 6. Ligand-receptor interaction results of sitagliptin with DPP4. (A) Three-dimensional (3D) representation of sitagliptin in complex with DPP4 with the highest binding energy of $-8.6 \mathrm{kcal} / \mathrm{mol}$. (B) Two-dimensional (2D) representation of sitagliptin in complex with DPP4, showing interactions with two conventional H-bonds, with interactions further stabilized by different amino acids around the sitagliptin backbone. The accompanying table shows summary results of the analysis.

\subsection{Molecular Docking Revealed Potential Inhibitory Effects of Sitagliptin on the MET Oncogene}

Our docking analysis revealed that sitagliptin exhibited a high binding energy of $-7.6 \mathrm{kcal} / \mathrm{mol}$ with the $M E T$ oncogene, the same as its FDA-approved inhibitor, crizotinib, which showed a binding affinity of $-7.6 \mathrm{kcal} / \mathrm{mol}$. Further analysis of the docking results showed that sitagliptin bound to the binding pocket of the MET oncogene by 4 conventional hydrogen bonds with shorter binding distances with TRY631 (2.07 $)$ and ARG125 (2.71 $)$ ). Interactions were further stabilized by a salt bridge (GLU205 and GLU206), van der Waals forces (TRP629, VAL656, VAL711, HIS740, and ASN710), carbon-hydrogen bond (SER630), Pi-Pi stacked (TYR547), Pi-Pi T-shaped (TYR666), amide Pi-stacked (TYR662), and Pi-alkyl (PHE357) around the sitagliptin backbone. However, results displayed of the crizotinib/MET complex did not exhibit conventional hydrogen bonds in the binding pocket of the MET oncogene. This suggests that sitagliptin has high potential to target $M E T$, compared with its standard inhibitor, crizotinib (Figure 8). 

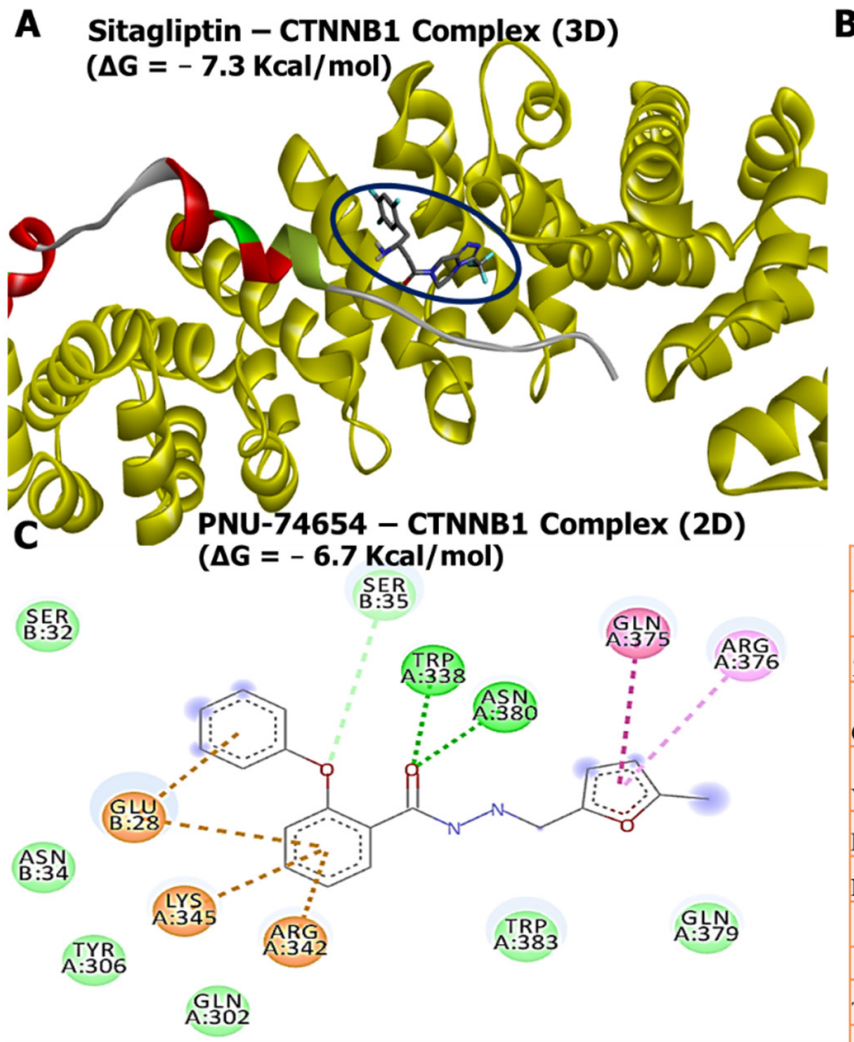

B Sitagliptin - CTNNB1 Complex (2D)

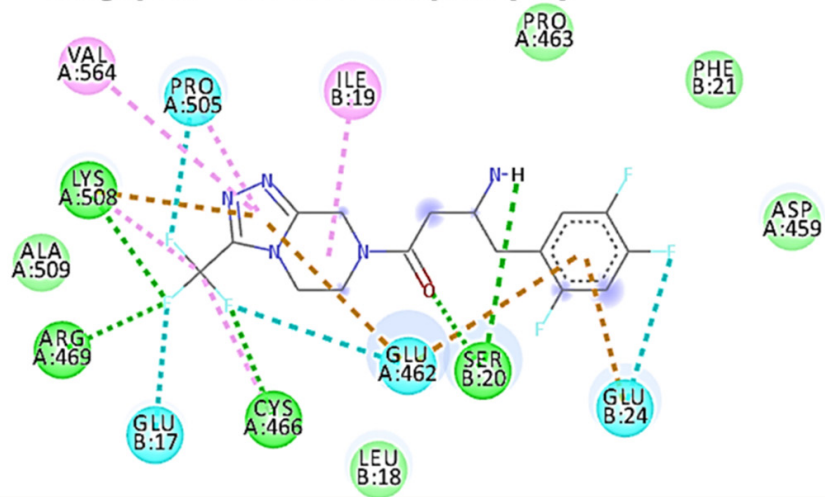

Sitagliptin - CTNNB1 Complex

$(\Delta \mathrm{G}=-7.3 \mathrm{Kcal} / \mathrm{mol})$

Type of interactions and number of bonds Distance of intercating Amino acids

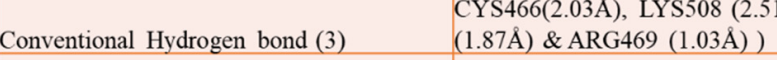

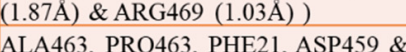

Van der Waals forces $\quad$ LEU18

Halogen (Flourine) GLU17, PRO505, GLU462 \& GLU24

Pi-Alkyl VAL564 \& ILE17

\begin{tabular}{|l|l|}
\hline \multicolumn{2}{|c|}{ PNU-74654-CTNNB1 Complex } \\
\hline \multicolumn{2}{|c|}{$(\mathbf{\Delta G}=-\mathbf{6 . 7}$ Kcal/mol) } \\
\hline Type of interactions and number of bonds & Distance of intercating Amino acids \\
\hline Conventional Hydrogen bond (3) & TRP338(2.09 $\AA)$ \& ASN380 (2.22 $\AA)$ \\
\hline Van der Waals forces & SER32, TYR306 and SER335 \\
\hline Amide Pi-Stacked & GLU375 \\
\hline Pi-Cation & GLU28, LYS345 \& ARG342 \\
\hline
\end{tabular}

Figure 7. In silico molecular docking analysis of ligand-protein interactions. (A) Three-dimensional (3D) representation of sitagliptin in complex with CTNNB1 with a binding energy of $-7.3 \mathrm{kcal} / \mathrm{mol}$. (B) Two-dimensional (2D) representation of sitagliptin in complex with CTNNB1, showing interactions with four conventional H-bonds and shorter binding distances, with interactions further stabilized by different amino acids around the sitagliptin backbone. (C) Two-dimensional (2D) representation of PNU-74654 in complex with CTNNB1, displaying lower binding energy of $-6.7 \mathrm{kcal} / \mathrm{mol}$, and interactions with (2) conventional hydrogen bonds with longer binding distances compared with that of sitagliptin, in the binding pockets of CTNNB1. The accompanying table shows a summary of the results. 


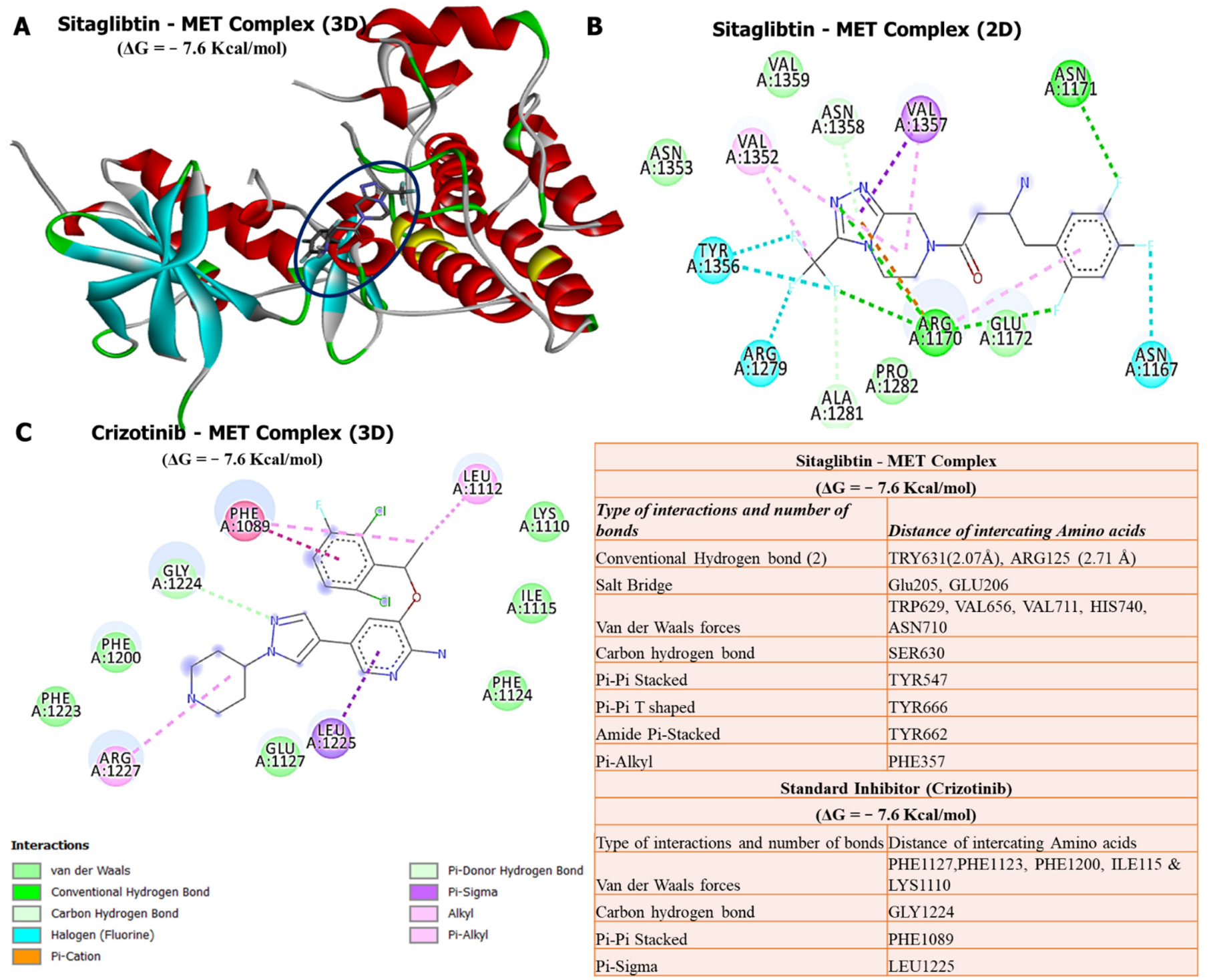

Figure 8. In silico molecular docking analysis of ligand-protein interactions. (A) Three-dimensional (3D) representation of sitagliptin in complex with $M E T$ with a binding energy of $-7.6 \mathrm{kcal} / \mathrm{mol}$. (B) Two-dimensional (2D) representation of sitagliptin in complex with $M E T$, showing interactions with conventional H-bonds and different amino acids. (C) Two-dimensional (2D) representation of crizotinib in complex with $M E T$, exhibiting the same binding energy as sitagliptin, but no interaction with conventional hydrogen bonds. The accompanying table shows a summary of the results.

\section{Discussion}

PTCa is the most prevalent type of THCA, which accounts for approximately $80 \%$ of all THCAs, consequently promoting cancer invasion, metastasis, and mortality in patients $[69,70]$. PTCa has recently been managed with a thyroidectomy; however, due to distant metastasis, THCA tends to be extremely aggressive, and resistant to treatment leading to poor prognoses [71-73]. Treatment modalities for THCA include the use of doxorubicin, but this has proven not to be very effective due to the development of resistance [1,74-76]. As a result, there is an urgent need to understand the molecular mechanisms associated with THCA metastasis, which will help in developing more effective treatments $[15,77]$. Identification of reliable biomarkers which can be used as diagnostic measures is urgently needed in PTCa. Most cancer therapeutic drugs have been shown to be cytotoxic and nonspecific to cancer cells, as they also affect normal cells and consequently cause harm to the body. 
In the present study, we evaluated the anticancer effects of the antidiabetic drug sitagliptin, which was recently shown to possess anticancer activities, and is well tolerated and effective. Sitagliptin is an FDA-approved DPP4 oncogene [78]. To further analyze sitagliptin, we explored computer-based simulations to identify and predict target genes, which are commonly overexpressed and associated with THCA invasion, progression, metastasis, poor prognosis, and resistance to therapeutics. We utilized microarray datasets from the NCBI-GEO, and identified DEGs in THCA compared to normal tissues. Among the top upregulated genes, were the DPP4, CTNNB1, and MET oncogenes. To validate their expressions, we used the UALCAN online bioinformatics tool with default settings, which showed that mRNA levels of DPP4/CTNNB1/MET were higher in THCA tumor tissues compared with adjacent normal tissues. Moreover, after exploring the TNMplot software, for further analysis, we identified that overexpression of DPP4/CTNNB1/MET gene signatures promoted THCA metastasis, and were associated with poor disease-free survival and poor prognoses.

The complex and dynamic interactions of immune cells, stoma, and cancer cells within the tumor microenvironment (TME) play a pivotal role in tumor invasion, cancer progression, and host immune response [62,79]. Consequently, our analysis of tumor immune infiltrating cells within the TME of THCA tumor revealed that the high expression levels of the DPP4/CTNNB1/MET signature correlate positively with the infiltration levels of tumor-associated macrophages, regulatory $\mathrm{T}$ cell, and cancer-associated fibroblast. These immunosuppressive cells are known to exert an inhibitory role on cytotoxic lymphocytes' function leading to T cell exclusion and tumor invasive phenotype [59,80]. In contrast, we found a strong negative association was observed between the mRNA expression levels of DPP4/CTNNB1/MET and immune infiltration level of $\mathrm{CD}^{+} \mathrm{T}$ cell, suggesting that high expression levels of DPP4/CTNNB1/MET are associated with immunosuppressive phenotypes via a mechanism involving T cell exclusion in THCA tissues

Molecular docking has become an increasingly important tool commonly used to understand drug bimolecular interactions with the target proteins for rational drug design and development $[62,81,82]$. It is useful in estimating binding affinities of the ligand to the proteins and in providing preliminary mechanistic insight into the behavior of a small molecule drug in the binding cavity of target proteins $[83,84]$, as well as elucidating the potential drug-regulated biochemical processes $[79,85]$. Consequently, we conducted a molecular docking analysis of interactions of DPP4/CTNNB1/MET gene signatures with sitagliptin. As expected, sitagliptin exhibited a higher binding energy of $-8.6 \mathrm{kcal} / \mathrm{mol}$ with the DPP4 oncogene. Furthermore, our docking analysis revealed that sitagliptin exhibited a higher binding energy of $-7.3 \mathrm{kcal} / \mathrm{mol}$ with the CTNNB1 oncogene compared with its FDA-approved inhibitor, PNU-74654, which showed a lower binding affinity of $-6.7 \mathrm{kcal} / \mathrm{mol}$. Our analysis showed that sitagliptin bound to the binding pocket of the CTNNB1 oncogene by 4 conventional hydrogen bonds and had shorter binding distances

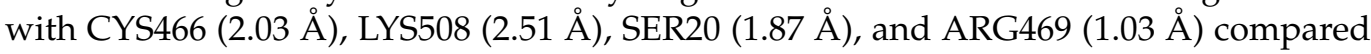
with PNU-74654, which bound to the binding pocket of the CTNNB1 oncogene by only 2 conventional hydrogen bonds, and had longer binding distances compared with sitagliptin. In addition, analytical results of sitagliptin in complex with $M E T$ exhibited the same binding energy of $-7.6 \mathrm{kcal} / \mathrm{mol}$ as the MET FDA-approved inhibitor, crizotinib. Sitagliptin bound to the binding pocket of the MET oncogene by 4 conventional hydrogen bonds and shorter binding distances with TRY631 (2.07 $\AA$ ) and ARG125 (2.71 A). However, results displayed from the crizotinib/MET complex did not exhibit conventional hydrogen bonds in the binding pocket of the MET oncogene.

In summary, these docking results suggest that sitagliptin has high potential to target DPP4/CTNNB1/MET signaling pathways in THCA compared with their standard inhibitors. Since recent studies have shown the efficacy and tolerance of sitagliptin as cancer therapeutic, it would be interesting to further investigate its activities as a target for DPP4/CTNNB1/MET signaling pathways in THCA, both in vitro and in vitro in tumor-bearing mice. 


\section{Conclusions}

In summary, we revealed that DPP4, CTNNB1, and MET oncogenic signatures are overexpressed in THCA, and are associated with cancer progression, metastasis, resistance, poor disease-free survival, and unfavorable clinical outcomes. Moreover, an in silico molecular docking study exhibited putative binding affinities of sitagliptin with the abovementioned oncogenes, which were higher than the standard inhibitors of these genes. This suggests that sitagliptin could be a potential THCA therapeutic, since it has been shown to be more tolerable and effective in different cancers.

Author Contributions: S.-Y.C., A.T.H.W., G.E.-S.B., C.-L.H., J.-C.L., H.Y.L., M.A., A.N.A. and J.-H.C. contributed to data analysis, and drafting or revising the article. All authors have read and agreed to the published version of the manuscript.

Funding: The current work was partly supported by Taif University Researchers Supporting Project number (TURSP-2020/310), Taif University, Taif, Saudi Arabia. Jia-Hong Chen was supported by TSGH-C03-111030; Ching-Liang Ho was funded by TSGH-C03-110022 and TSGH-C02-111024; JihChin Lee was supported by TSGH-D-110079 and TSGH-D-111060; Alexander TH Wu was financially supported by the "TMU Research Center of Cancer Translational Medicine" from The Featured Areas Research Center Program within the framework of the Higher Education Sprout Project by the Ministry of Education (MOE) in Taiwan. (Grant number: DP2-110-21121-03-C-09).

Institutional Review Board Statement: Not applicable.

Informed Consent Statement: Not applicable.

Data Availability Statement: The datasets generated and analyzed in this study can be made available upon reasonable request.

Acknowledgments: The authors express their thanks to Taif University for supporting the projectTURSP 2020/310.

Conflicts of Interest: The authors declare no conflict of interest.

\section{References}

1. Nguyen, Q.T.; Lee, E.J.; Huang, M.G.; Park, Y.I.; Khullar, A.; Plodkowski, R.A. Diagnosis and treatment of patients with thyroid cancer. Am. Health Drug Benefits 2015, 8, 30-40. [PubMed]

2. Siegel, R.L.; Miller, K.D.; Jemal, A. Cancer statistics, 2020. CA Cancer J. Clin. 2020, 70, 7-30. [CrossRef] [PubMed]

3. Bray, F.; Ferlay, J.; Soerjomataram, I.; Siegel, R.L.; Torre, L.A.; Jemal, A. Global cancer statistics 2018: GLOBOCAN estimates of incidence and mortality worldwide for 36 cancers in 185 countries. CA Cancer J. Clin. 2018, 68, 394-424. [CrossRef] [PubMed]

4. La Vecchia, C.; Malvezzi, M.; Bosetti, C.; Garavello, W.; Bertuccio, P.; Levi, F.; Negri, E. Thyroid cancer mortality and incidence: A global overview. Int. J. Cancer 2015, 136, 2187-2195. [CrossRef] [PubMed]

5. Roman, B.R.; Morris, L.G.; Davies, L. The thyroid cancer epidemic, 2017 perspective. Curr. Opin. Endocrinol. Diabetes Obes. 2017, 24, 332-336. [CrossRef]

6. Siegel, R.L.; Miller, K.D.; Fuchs, H.E.; Jemal, A. Cancer Statistics, 2021. CA Cancer J. Clin. 2021, 71, 7-33. [CrossRef]

7. Fagin, J.A.; Wells, S.A., Jr. Biologic and clinical perspectives on thyroid cancer. N. Engl. J. Med. 2016, 375, 1054-1067. [CrossRef]

8. Molinaro, E.; Romei, C.; Biagini, A.; Sabini, E.; Agate, L.; Mazzeo, S.; Materazzi, G.; Sellari-Franceschini, S.; Ribechini, A.; Torregrossa, L. Anaplastic thyroid carcinoma: From clinicopathology to genetics and advanced therapies. Nat. Rev. Endocrinol. 2017, 13, 644-660. [CrossRef]

9. Knauf, J.A.; Ma, X.; Smith, E.P.; Zhang, L.; Mitsutake, N.; Liao, X.-H.; Refetoff, S.; Nikiforov, Y.E.; Fagin, J.A. Targeted expression of BRAFV600E in thyroid cells of transgenic mice results in papillary thyroid cancers that undergo dedifferentiation. Cancer Res. 2005, 65, 4238-4245. [CrossRef]

10. Brito, J.P.; Morris, J.C.; Montori, V.M. Thyroid cancer: Zealous imaging has increased detection and treatment of low risk tumours. BMJ 2013, 347, f4706. [CrossRef]

11. Udelsman, R.; Zhang, Y. The epidemic of thyroid cancer in the United States: The role of endocrinologists and ultrasounds. Thyroid 2014, 24, 472-479. [CrossRef]

12. Furuya-Kanamori, L.; Bell, K.J.; Clark, J.; Glasziou, P. Prevalence of differentiated thyroid cancer in autopsy studies over six decades: A meta-analysis. J. Clin. Oncol. 2016, 34, 3672-3679. [CrossRef] [PubMed]

13. Ahn, H.S.; Welch, H.G. South Korea's thyroid-cancer "epidemic"-Turning the tide. N. Engl. J. Med. 2015, 373, 2389-2390. [CrossRef] [PubMed]

14. Kitahara, C.M.; Schneider, A.; Brenner, A.V. Chapter 44: Thyroid cancer. In Cancer Epidemiology and Prevention, 4th ed.; Schottenfeld, D., Fraumeni, J., Eds.; Oxford University Press: New York, NY, USA, 2016; pp. 839-860. 
15. Wei, W.J.; Zhang, G.Q.; Luo, Q.Y. Postsurgical Management of Differentiated Thyroid Cancer in China. Trends Endocrinol. Metab. 2018, 29, 71-73. [CrossRef] [PubMed]

16. Nikiforov, Y.E.; Nikiforova, M.N. Molecular genetics and diagnosis of thyroid cancer. Nat. Rev. Endocrinol. 2011, 7, 569-580. [CrossRef] [PubMed]

17. Long, K.L.; Grubbs, E.G. Carcinoma of the thyroid gland and neoplasms of the parathyroid glands. In The MD Anderson Surgical Oncology Handbook, 6th ed.; Wolters Kluwer Health Adis (ESP): London, UK, 2018; pp. 463-491.

18. Ho, A.S.; Luu, M.; Barrios, L.; Chen, I.; Melany, M.; Ali, N.; Patio, C.; Chen, Y.; Bose, S.; Fan, X.; et al. Incidence and Mortality Risk Spectrum Across Aggressive Variants of Papillary Thyroid Carcinoma. JAMA Oncol. 2020, 6, 706-713. [CrossRef] [PubMed]

19. Bai, Y.; Kakudo, K.; Jung, C.K. Updates in the Pathologic Classification of Thyroid Neoplasms: A Review of the World Health Organization Classification. Endocrinol. Metab. 2020, 35, 696-715. [CrossRef]

20. WHO. WHO Classification of Tumours of Endocrine Organs; IARC: Lion, France, 2017.

21. Nath, M.C.; Erickson, L.A. Aggressive Variants of Papillary Thyroid Carcinoma: Hobnail, Tall Cell, Columnar, and Solid. Adv. Anat. Pathol. 2018, 25, 172-179. [CrossRef]

22. Cavaco, D.; Martins, A.F.; Cabrera, R.; Vilar, H.; Leite, V. Diffuse sclerosing variant of papillary thyroid carcinoma: Outcomes of 33 cases. Eur. Thyroid. J. 2022, 11, e210020. [CrossRef]

23. Roman, S.; Sosa, J.A. Aggressive variants of papillary thyroid cancer. Curr. Opin. Oncol. 2013, 25, 33-38. [CrossRef]

24. Besic, N.; Auersperg, M.; Dremelj, M.; Vidergar-Kralj, B.; Gazic, B. Neoadjuvant chemotherapy in 16 patients with locally advanced papillary thyroid carcinoma. Thyroid 2013, 23, 178-184. [CrossRef] [PubMed]

25. Giuffrida, R.; Adamo, L.; Iannolo, G.; Vicari, L.; Giuffrida, D.; Eramo, A.; Gulisano, M.; Memeo, L.; Conticello, C. Resistance of papillary thyroid cancer stem cells to chemotherapy. Oncol. Lett. 2016, 12, 687-691. [CrossRef] [PubMed]

26. Kim, K.B.; Cabanillas, M.E.; Lazar, A.J.; Williams, M.D.; Sanders, D.L.; Ilagan, J.L.; Nolop, K.; Lee, R.J.; Sherman, S.I. Clinical responses to vemurafenib in patients with metastatic papillary thyroid cancer harboring BRAF(V600E) mutation. Thyroid 2013, 23, 1277-1283. [CrossRef] [PubMed]

27. Noels, H.; Theelen, W.; Sternkopf, M.; Jankowski, V.; Moellmann, J.; Kraemer, S.; Lehrke, M.; Marx, N.; Martin, L.; Marx, G.; et al. Reduced post-operative DPP4 activity associated with worse patient outcome after cardiac surgery. Sci. Rep. 2018, 8, 11820. [CrossRef]

28. Javidroozi, M.; Zucker, S.; Chen, W.T. Plasma seprase and DPP4 levels as markers of disease and prognosis in cancer. Dis. Markers 2012, 32, 309-320. [CrossRef] [PubMed]

29. Lee, J.J.; Wang, T.Y.; Liu, C.L.; Chien, M.N.; Chen, M.J.; Hsu, Y.C.; Leung, C.H.; Cheng, S.P. Dipeptidyl Peptidase IV as a Prognostic Marker and Therapeutic Target in Papillary Thyroid Carcinoma. J. Clin. Endocrinol. Metab. 2017, 102, 2930-2940. [CrossRef]

30. Kotani, T.; Aratake, Y.; Ogata, Y.; Umeki, K.; Araki, Y.; Hirai, K.; Kuma, K.; Ohtaki, S. Expression of dipeptidyl aminopeptidase IV activity in thyroid carcinoma. Cancer Lett. 1991, 57, 203-208. [CrossRef]

31. Aratake, Y.; Kotani, T.; Tamura, K.; Araki, Y.; Kuribayashi, T.; Konoe, K.; Ohtaki, S. Dipeptidyl aminopeptidase IV staining of cytologic preparations to distinguish benign from malignant thyroid diseases. Am. J. Clin. Pathol. 1991, 96, 306-310. [CrossRef]

32. Nouraee, N.; Van Roosbroeck, K.; Vasei, M.; Semnani, S.; Samaei, N.M.; Naghshvar, F.; Omidi, A.A.; Calin, G.A.; Mowla, S.J. Expression, tissue distribution and function of miR-21 in esophageal squamous cell carcinoma. PLoS ONE 2013, 8, e73009. [CrossRef]

33. Pang, R.; Law, W.L.; Chu, A.C.; Poon, J.T.; Lam, C.S.; Chow, A.K.; Ng, L.; Cheung, L.W.; Lan, X.R.; Lan, H.Y.; et al. A subpopulation of CD26+ cancer stem cells with metastatic capacity in human colorectal cancer. Cell Stem Cell 2010, 6, 603-615. [CrossRef]

34. Liu, L.; Yan, M.; Zhao, F.; Li, J.; Ge, C.; Geng, Q.; Zhu, M.; Sun, L.; He, X.; Li, J. CD26/dipeptidyl peptidase IV contributes to tumor metastasis in human lung adenocarcinoma. Bangladesh J. Pharmacol. 2013, 8, 198-206. [CrossRef]

35. Jang, J.; Haberecker, M.; Curioni, A.; Janker, F.; Soltermann, A.; Gil-Bazo, I.; Hwang, I.; Kwon, K.; Weder, W.; Jungraithmayr, W. EP1.03-33 CD26/DPP4 as a Novel Prognostic Marker for Lung Adenocarcinoma. J. Thorac. Oncol. 2019, 14, S965. [CrossRef]

36. Lu, Z.; Qi, L.; Bo, X.J.; Liu, G.D.; Wang, J.M.; Li, G. Expression of CD26 and CXCR4 in prostate carcinoma and its relationship with clinical parameters. J. Res. Med. 2013, 18, 647-652.

37. Kretzschmar, K.; Weber, C.; Driskell, R.R.; Calonje, E.; Watt, F.M. Compartmentalized Epidermal Activation of $\beta$-Catenin Differentially Affects Lineage Reprogramming and Underlies Tumor Heterogeneity. Cell Rep. 2016, 14, 269-281. [CrossRef]

38. Dong, C.; Yang, H.; Wang, Y.; Yan, X.; Li, D.; Cao, Z.; Ning, Y.; Zhang, C. Anagliptin stimulates osteoblastic cell differentiation and mineralization. Biomed. Pharmacother. 2020, 129, 109796. [CrossRef]

39. Ren, X.; Zhu, R.; Liu, G.; Xue, F.; Wang, Y.; Xu, J.; Zhang, W.; Yu, W.; Li, R. Effect of sitagliptin on tubulointerstitial Wnt/ $\beta$-catenin signalling in diabetic nephropathy. Nephrology 2019, 24, 1189-1197. [CrossRef]

40. Garcia, C.; Buffet, C.; El Khattabi, L.; Rizk-Rabin, M.; Perlemoine, K.; Ragazzon, B.; Bertherat, J.; Cormier, F.; Groussin, L. MET overexpression and activation favors invasiveness in a model of anaplastic thyroid cancer. Oncotarget 2019, 10, $2320-2334$. [CrossRef]

41. Trovato, M.; Campennì, A.; Giovinazzo, S.; Siracusa, M.; Ruggeri, R.M. Hepatocyte Growth Factor/C-Met Axis in Thyroid Cancer: From Diagnostic Biomarker to Therapeutic Target. Biomark. Insights 2017, 12, 1177271917701126. [CrossRef]

42. Mineo, R.; Costantino, A.; Frasca, F.; Sciacca, L.; Russo, S.; Vigneri, R.; Belfiore, A. Activation of the hepatocyte growth factor (HGF)-Met system in papillary thyroid cancer: Biological effects of HGF in thyroid cancer cells depend on Met expression levels. Endocrinology 2004, 145, 4355-4365. [CrossRef] 
43. Di Renzo, M.F.; Olivero, M.; Ferro, S.; Prat, M.; Bongarzone, I.; Pilotti, S.; Belfiore, A.; Costantino, A.; Vigneri, R.; Pierotti, M.A.; et al. Overexpression of the c-MET/HGF receptor gene in human thyroid carcinomas. Oncogene 1992, 7, 2549-2553. [PubMed]

44. Lesko, E.; Majka, M. The biological role of HGF-MET axis in tumor growth and development of metastasis. Front. Biosci. 2008, 13, 1271-1280. [CrossRef] [PubMed]

45. Monga, S.P.; Mars, W.M.; Pediaditakis, P.; Bell, A.; Mulé, K.; Bowen, W.C.; Wang, X.; Zarnegar, R.; Michalopoulos, G.K. Hepatocyte growth factor induces Wnt-independent nuclear translocation of beta-catenin after Met-beta-catenin dissociation in hepatocytes. Cancer Res. 2002, 62, 2064-2071. [PubMed]

46. Tward, A.D.; Jones, K.D.; Yant, S.; Cheung, S.T.; Fan, S.T.; Chen, X.; Kay, M.A.; Wang, R.; Bishop, J.M. Distinct pathways of genomic progression to benign and malignant tumors of the liver. Proc. Natl. Acad. Sci. USA 2007, 104, 14771-14776. [CrossRef]

47. Sastre-Perona, A.; Santisteban, P. Role of the wnt pathway in thyroid cancer. Front. Endocrinol. 2012, 3, 31. [CrossRef]

48. Rezk, S.; Brynes, R.K.; Nelson, V.; Thein, M.; Patwardhan, N.; Fischer, A.; Khan, A. beta-Catenin expression in thyroid follicular lesions: Potential role in nuclear envelope changes in papillary carcinomas. Endocr. Pathol. 2004, 15, 329-337. [CrossRef]

49. Buchanan, S.G.; Hendle, J.; Lee, P.S.; Smith, C.R.; Bounaud, P.Y.; Jessen, K.A.; Tang, C.M.; Huser, N.H.; Felce, J.D.; Froning, K.J.; et al. SGX523 is an exquisitely selective, ATP-competitive inhibitor of the MET receptor tyrosine kinase with antitumor activity in vivo. Mol. Cancer 2009, 8, 3181-3190. [CrossRef]

50. Amritha, C.A.; Kumaravelu, P.; Chellathai, D.D. Evaluation of Anti Cancer Effects of DPP-4 Inhibitors in Colon Cancer- An Invitro Study. J. Clin. Diagn. Res. 2015, 9, Fc14-Fc16. [CrossRef]

51. Chandrashekar, D.S.; Bashel, B.; Balasubramanya, S.A.H.; Creighton, C.J.; Ponce-Rodriguez, I.; Chakravarthi, B.; Varambally, S. UALCAN: A Portal for Facilitating Tumor Subgroup Gene Expression and Survival Analyses. Neoplasia 2017, 19, 649-658. [CrossRef]

52. Gao, J.; Aksoy, B.A.; Dogrusoz, U.; Dresdner, G.; Gross, B.; Sumer, S.O.; Sun, Y.; Jacobsen, A.; Sinha, R.; Larsson, E.; et al. Integrative analysis of complex cancer genomics and clinical profiles using the cBioPortal. Sci. Signal. 2013, 6, pl1. [CrossRef]

53. Bartha, Á.; Győrffy, B. TNMplot.com: A Web Tool for the Comparison of Gene Expression in Normal, Tumor and Metastatic Tissues. Int. J. Mol. Sci. 2021, 22, 2622. [CrossRef] [PubMed]

54. Szklarczyk, D.; Gable, A.L.; Lyon, D.; Junge, A.; Wyder, S.; Huerta-Cepas, J.; Simonovic, M.; Doncheva, N.T.; Morris, J.H.; Bork, P.; et al. STRING v11: Protein-protein association networks with increased coverage, supporting functional discovery in genome-wide experimental datasets. Nucleic Acids Res. 2019, 47, D607-D613. [CrossRef] [PubMed]

55. Franz, M.; Rodriguez, H.; Lopes, C.; Zuberi, K.; Montojo, J.; Bader, G.D.; Morris, Q. GeneMANIA update 2018. Nucleic Acids Res. 2018, 46, W60-W64. [CrossRef] [PubMed]

56. Zhou, G.; Soufan, O.; Ewald, J.; Hancock, R.E.W.; Basu, N.; Xia, J. NetworkAnalyst 3.0: A visual analytics platform for comprehensive gene expression profiling and meta-analysis. Nucleic Acids Res. 2019, 47, W234-W241. [CrossRef] [PubMed]

57. Pathan, M.; Keerthikumar, S.; Ang, C.S.; Gangoda, L.; Quek, C.Y.; Williamson, N.A.; Mouradov, D.; Sieber, O.M.; Simpson, R.J.; Salim, A.; et al. FunRich: An open access standalone functional enrichment and interaction network analysis tool. Proteomics 2015, 15, 2597-2601. [CrossRef] [PubMed]

58. Juneja, M.; Kobelt, D.; Walther, W.; Voss, C.; Smith, J.; Specker, E.; Neuenschwander, M.; Gohlke, B.-O.; Dahlmann, M.; Radetzki, S.; et al. Statin and rottlerin small-molecule inhibitors restrict colon cancer progression and metastasis via MACC1. PLoS Biol. 2017, 15, e2000784. [CrossRef]

59. Lawal, B.; Lin, L.-C.; Lee, J.-C.; Chen, J.-H.; Bekaii-Saab, T.S.; Wu, A.T.H.; Ho, C.-L. Multi-Omics Data Analysis of Gene Expressions and Alterations, Cancer-Associated Fibroblast and Immune Infiltrations, Reveals the Onco-Immune Prognostic Relevance of STAT3/CDK2/4/6 in Human Malignancies. Cancers 2021, 13, 954. [CrossRef]

60. Lawal, B.; Tseng, S.-H.; Olugbodi, J.O.; Iamsaard, S.; Ilesanmi, O.B.; Mahmoud, M.H.; Ahmed, S.H.; Batiha, G.E.-S.; Wu, A.T.H. Pan-Cancer Analysis of Immune Complement Signature C3/C5/C3AR1/C5AR1 in Association with Tumor Immune Evasion and Therapy Resistance. Cancers 2021, 13, 4124. [CrossRef]

61. Seeliger, D.; de Groot, B.L. Ligand docking and binding site analysis with PyMOL and Autodock/Vina. J. Comput. Aided Mol. Des. 2010, 24, 417-422. [CrossRef]

62. Wu, S.-Y.; Lin, K.-C.; Lawal, B.; Wu, A.T.H.; Wu, C.-Z. MXD3 as an onco-immunological biomarker encompassing the tumor microenvironment, disease staging, prognoses, and therapeutic responses in multiple cancer types. Comput. Struct. Biotechnol. J. 2021, 19, 4970-4983. [CrossRef]

63. Wu, A.T.H.; Lawal, B.; Tzeng, Y.-M.; Shih, C.-C.; Shih, C.-M. Identification of a Novel Theranostic Signature of Metabolic and Immune-Inflammatory Dysregulation in Myocardial Infarction, and the Potential Therapeutic Properties of Ovatodiolide, a Diterpenoid Derivative. Int. J. Mol. Sci. 2022, 23, 1281. [CrossRef] [PubMed]

64. Wu, A.T.H.; Lawal, B.; Wei, L.; Wen, Y.-T.; Tzeng, D.T.W.; Lo, W.-C. Multiomics Identification of Potential Targets for Alzheimer Disease and Antrocin as a Therapeutic Candidate. Pharmaceutics 2021, 13, 1555. [CrossRef] [PubMed]

65. Goodsell, D.S.; Sanner, M.F.; Olson, A.J.; Forli, S. The AutoDock suite at 30. Protein Sci. 2021, 30, 31-43. [CrossRef]

66. Mokgautsi, N.; Wen, Y.-T.; Lawal, B.; Khedkar, H.; Sumitra, M.R.; Wu, A.T.; Huang, H.-S. An integrated bioinformatics study of a novel niclosamide derivative, nsc765689, a potential gsk3 $\beta / \beta$-catenin/stat3/cd44 suppressor with anti-glioblastoma properties. Int. J. Mol. Sci. 2021, 22, 2464. [CrossRef] [PubMed] 
67. Lawal, B.; Liu, Y.-L.; Mokgautsi, N.; Khedkar, H.; Sumitra, M.R.; Wu, A.T.H.; Huang, H.-S. Pharmacoinformatics and Preclinical Studies of NSC765690 and NSC765599, Potential STAT3/CDK2/4/6 Inhibitors with Antitumor Activities against NCI60 Human Tumor Cell Lines. Biomedicines 2021, 9, 92. [CrossRef] [PubMed]

68. Raman, E.P.; Paul, T.J.; Hayes, R.L.; Brooks, C.L., 3rd. Automated, Accurate, and Scalable Relative Protein-Ligand Binding Free-Energy Calculations Using Lambda Dynamics. J. Chem. Theory Comput. 2020, 16, 7895-7914. [CrossRef]

69. Huang, Y.; Prasad, M.; Lemon, W.J.; Hampel, H.; Wright, F.A.; Kornacker, K.; LiVolsi, V.; Frankel, W.; Kloos, R.T.; Eng, C.; et al. Gene expression in papillary thyroid carcinoma reveals highly consistent profiles. Proc. Natl. Acad. Sci. USA 2001, 98, 15044-15049. [CrossRef]

70. Petrakis, D.; Vassilopoulou, L.; Mamoulakis, C.; Psycharakis, C.; Anifantaki, A.; Sifakis, S.; Docea, A.O.; Tsiaoussis, J.; Makrigiannakis, A.; Tsatsakis, A.M. Endocrine Disruptors Leading to Obesity and Related Diseases. Int. J. Environ. Res. Public Health 2017, 14, 1282. [CrossRef]

71. Takano, T. Natural history of thyroid cancer [Review]. Endocr. J. 2017, 64, 237-244. [CrossRef]

72. Schlumberger, M.; Parmentier, C.; Delisle, M.J.; Couette, J.E.; Droz, J.P.; Sarrazin, D. Combination therapy for anaplastic giant cell thyroid carcinoma. Cancer 1991, 67, 564-566. [CrossRef]

73. Tennvall, J.; Lundell, G.; Wahlberg, P.; Bergenfelz, A.; Grimelius, L.; Akerman, M.; Hjelm Skog, A.L.; Wallin, G. Anaplastic thyroid carcinoma: Three protocols combining doxorubicin, hyperfractionated radiotherapy and surgery. Br. J. Cancer 2002, 86, 1848-1853. [CrossRef] [PubMed]

74. Ancker, O.V.; Krüger, M.; Wehland, M.; Infanger, M.; Grimm, D. Multikinase Inhibitor Treatment in Thyroid Cancer. Int. J. Mol. Sci. 2019, 21, 10. [CrossRef] [PubMed]

75. O'Neill, C.J.; Oucharek, J.; Learoyd, D.; Sidhu, S.B. Standard and emerging therapies for metastatic differentiated thyroid cancer. Oncologist 2010, 15, 146-156. [CrossRef] [PubMed]

76. Kapiteijn, E.; Schneider, T.C.; Morreau, H.; Gelderblom, H.; Nortier, J.W.R.; Smit, J.W.A. New treatment modalities in advanced thyroid cancer. Ann. Oncol. 2012, 23, 10-18. [CrossRef] [PubMed]

77. Tang, M.; Wang, Q.; Wang, K.; Wang, F. Mesenchymal stem cells-originated exosomal microRNA-152 impairs proliferation, invasion and migration of thyroid carcinoma cells by interacting with DPP4. J. Endocrinol. Investig. 2020, 43, 1787-1796. [CrossRef] [PubMed]

78. Tseng, C.H. Sitagliptin use and thyroid cancer risk in patients with type 2 diabetes. Oncotarget 2016, 7, 24871-24879. [CrossRef]

79. Chen, J.-H.; Wu, A.T.H.; Lawal, B.; Tzeng, D.T.W.; Lee, J.-C.; Ho, C.-L.; Chao, T.-Y. Identification of Cancer Hub Gene Signatures Associated with Immune-Suppressive Tumor Microenvironment and Ovatodiolide as a Potential Cancer Immunotherapeutic Agent. Cancers 2021, 13, 3847. [CrossRef]

80. Lawal, B.; Lee, C.-Y.; Mokgautsi, N.; Sumitra, M.R.; Khedkar, H.; Wu, A.T.H.; Huang, H.-S. mTOR/EGFR/iNOS/MAP2K1/FGFR/ TGFB1 Are Druggable Candidates for N-(2,4-Difluorophenyl)-2' , $^{\prime}$-Difluoro-4-Hydroxybiphenyl-3-Carboxamide (NSC765598), With Consequent Anticancer Implications. Front. Oncol. 2021, 11, 656738. [CrossRef]

81. Yeh, Y.-C.; Lawal, B.; Hsiao, M.; Huang, T.-H.; Huang, C.-Y.F. Identification of NSP3 (SH2D3C) as a Prognostic Biomarker of Tumor Progression and Immune Evasion for Lung Cancer and Evaluation of Organosulfur Compounds from Allium sativum L. as Therapeutic Candidates. Biomedicines 2021, 9, 1582. [CrossRef]

82. Lawal, B.; Wang, Y.-C.; Wu, A.T.H.; Huang, H.-S. Pro-Oncogenic c-Met/EGFR, Biomarker Signatures of the Tumor Microenvironment are Clinical and Therapy Response Prognosticators in Colorectal Cancer, and Therapeutic Targets of 3-Phenyl-2Hbenzo[e][1,3]-Oxazine-2,4(3H)-Dione Derivatives. Front. Pharmacol. 2021, 12, 691234. [CrossRef]

83. Lawal, B.; Kuo, Y.-C.; Tang, S.-L.; Liu, F.-C.; Wu, A.T.H.; Lin, H.-Y.; Huang, H.-S. Transcriptomic-Based Identification of the Immuno-Oncogenic Signature of Cholangiocarcinoma for HLC-018 Multi-Target Therapy Exploration. Cells 2021, $10,2873$. [CrossRef] [PubMed]

84. Lawal, B.; Kuo, Y.-C.; Sumitra, M.R.; Wu, A.T.; Huang, H.-S. In vivo Pharmacokinetic and Anticancer Studies of HH-N25, a Selective Inhibitor of Topoisomerase I, and Hormonal Signaling for Treating Breast Cancer. J. Inflamm. Res. 2021, 14, 1-13. [CrossRef] [PubMed]

85. Kitchen, D.B.; Decornez, H.; Furr, J.R.; Bajorath, J. Docking and scoring in virtual screening for drug discovery: Methods and applications. Nat. Rev. Drug Discov. 2004, 3, 935-949. [CrossRef] [PubMed] 